\title{
Research on Experimental Method for Obtaining Independent Combustion Noise of Internal Combustion Engine
}

\author{
Yang Xiang $\left.\mathbb{D}^{1}\right)^{1,2}$ Jiachi Yao $\mathbb{D}^{1,2}$ Qiang Zhou $\mathbb{D}^{1,2}$, Sichong Qian, ${ }^{1,2}$ and Shuai Wang ${ }^{1,2}$ \\ ${ }^{1}$ School of Energy and Power Engineering, Wuhan University of Technology, Wuhan 430063, China \\ ${ }^{2}$ Key Laboratory of Marine Power Engineering and Technology, Ministry of Communications, Wuhan University of Technology, \\ Wuhan 430063, China \\ Correspondence should be addressed to Yang Xiang; yxiang@whut.edu.cn
}

Received 7 July 2018; Revised 29 September 2018; Accepted 14 October 2018; Published 1 November 2018

Academic Editor: Zhixiong Li

Copyright (C) 2018 Yang Xiang et al. This is an open access article distributed under the Creative Commons Attribution License, which permits unrestricted use, distribution, and reproduction in any medium, provided the original work is properly cited.

\begin{abstract}
Internal combustion engine noise sources are complex and changeable. Combustion noise is usually drowned out by mechanical noise and aerodynamic noise. Traditional noise source identification methods can only qualitatively identify combustion noise. In order to quantitatively obtain the independent pure combustion noise of an internal combustion engine, it is necessary to design and build a separate noise source simulation test bench. In this paper, the combustion noise separation test bench based on transfer function method is designed and implemented. In the test, a pressure pulse device is installed in the combustion chamber. When the piston is at top dead center (TDC), pulse pressure is generated to excite the internal combustion engine to radiate noise. The pressure signal and noise signal are utilized to obtain the transfer function of combustion pressure and noise. Then, according to the cylinder pressure and transfer function, the combustion noise can be directly calculated. The test was carried out on $4120 \mathrm{SG}$ diesel engine. Experimental results show that when the internal combustion engine is under $1500 \mathrm{rpm}$ and no-load condition and $800 \mathrm{rpm}$ and no-load condition, the frequency components of independent pure combustion noise are both mainly concentrated at $1100 \mathrm{~Hz}, 1400 \mathrm{~Hz}$, and $3000 \mathrm{~Hz}$. Furthermore, the internal combustion engine vibration test method and the combustion noise empirical formula calculation method are both carried out to show accuracy and effectiveness of the obtained independent combustion noise through the combustion noise separation test based on transfer function method.
\end{abstract}

\section{Introduction}

The separation and identification technology of noise sources is an important research field of internal combustion engine. The main noise sources of internal combustion engines are combustion noise, mechanical noise, and aerodynamic noise $[1,2]$. When the internal combustion engine is working, the internal combustion engine will inevitably produce very loud noise, and the loud noise can cause harm to people, for example, it makes people irritable and anxious and even cause people diseases [3, 4]. At present, people are paying more and more attention to the influence of noise on the environment. Moreover, many countries have established noise control laws and regulations $[5,6]$. Therefore, reducing the noise of internal combustion engine is an urgent problem to be solved.

Before formulating the noise reduction plan for internal combustion engine, the first step is to analyse the acoustic characteristic information of independent noise sources. The noise source identification method of internal combustion engine can be divided into the traditional noise source identification method, the noise source identification method based on acoustic array technology, and the noise source identification method based on modern signal processing technology. Traditional noise source identification methods include subjective identification method, lead coverage method, spectrum analysis method, near field test method, and partial operation method. The traditional noise source identification method is simple and easy to operate, but the accuracy and precision of the noise source identification is low. The noise source identification methods based on acoustic array technology are mainly sound intensity method, acoustic holography method, and beam forming method [7]. The noise source identification method based on acoustic array technology is mainly used to 
determine the distribution of radiation noise on the surface of internal combustion engine, and it is impossible to obtain independent noise sources such as combustion noise and mechanical noise. The noise source identification methods based on modern signal processing technology are mainly included multichannel separation method and singlechannel separation method. For multichannel separation method, it mainly includes independent component analysis method $[8,9]$, filtering method $[10,11]$, wavelet transform and partial coherence analysis method [12], multiple regression analysis method [13-16], coherence method [17, 18], binaural sound localization method [19], and so on. Multichannel method requires multiple channels of sensors. For single-channel separation method, it mainly includes EMDbased method [20, 21], VMD-based method [22] and so on. Single-channel method requires only one channel of sensor. Compared with the traditional noise source identification method and the noise source identification method based on acoustic array technology, the noise source identification method based on modern signal processing technology can accurately separate the noise sources of internal combustion engine. However, the noise source of the internal combustion engine is complex, and the noise sources are seriously mixed with each other, thus it is impossible to get a completely pure independent noise source signal.

Currently, the noise source separation methods mainly adopt the multichannel separation method and the singlechannel separation method. The multichannel method requires the separation of noise source signals from signals of two or more channels. Obviously, two or more sensors are needed in this case. However, in engineering and practical applications, researchers often want to achieve the same noise source separation and identification effect with the fewest sensors. Thus, many researchers have studied using a single-channel method to separate noise sources.

When the noise sources are separated by the multichannel method or the single-channel method, the obtained noise sources may contain other interference components. In order to obtain more pure independent noise source, it is necessary to improve the performance of the multichannel method and the single-channel method. Considering this situation, the first thing is to obtain each independent pure noise sources of internal combustion engine. Thus, it is necessary to design a separate noise source acquisition experimental platform to obtain independent pure noise source signal. Among the noise sources of internal combustion engine, combustion noise is the main noise source of internal combustion engine, thus this paper is focused on the design and implementation of an independent combustion noise test bench for internal combustion engine.

To the knowledge of the authors, Shu et al. [23] employed a single cylinder internal combustion engine test bench to separate the combustion noise in 2005. Since 2005, there are very few studies on independent pure noise source test bench of internal combustion engine. This is because it is usually limited by experimental conditions, and it is very difficult to obtain independent pure independent noise sources. For the noise research field of internal combustion engine, it is important to design independent noise source test bench for internal combustion engine. On the one hand, by obtaining independent pure combustion noise and analysing its acoustic characteristic information, it can provide theoretical reference for internal combustion engine fault monitoring diagnosis [24-26]. On the other hand, if the independent pure noise sources of internal combustion engine can be obtained and made into a unified database, such as TIMIT database and noise database [27], it can provide convenience for analysing the acoustic characteristics of noise sources of internal combustion engine.

In this paper, the test object is a multicylinder internal combustion engine. Compared with previous research work [23], the design and implementation of the test platform are researched in more detail. In the process of the test, considering that internal combustion engine is a compression ignition mode without ignition device and the ignition device needs to be installed in the position of the original fuel injector, the self-designed ignition system device is similar to the shape of the injector. It has simple and practical features, and it can provide reference for further research. Before test, the internal combustion engine is worked enough time to ensure the state of internal combustion engine parameters is close to normal working conditions as far as possible. Then, a pressure pulse device is installed in the combustion chamber. When the piston is at top dead center, pulse pressure is generated to excite the internal combustion engine to radiate noise. The in-cylinder pulse pressure signal and its radiated noise signal are measured at the same time, and they are used to calculate the combustion noise transfer function. Finally, when the internal combustion engine is operating under normal conditions, the measured cylinder pressure signals and the calculated combustion noise transfer function are directly utilized to calculate the independent pure combustion noise. Moreover, the internal combustion engine vibration test method and the combustion noise empirical formula calculation method are further carried out to show accuracy and effectiveness of the obtained independent pure combustion noise.

The paper is organized as follows. In Section 2, generation mechanism of combustion noise is described. In Section 3, the internal combustion engine test bench is analysed and introduced. In Section 4, results and discussion are explained. Finally, Section 5 presents conclusions.

\section{Generation Mechanism of Combustion Noise}

The combustion noise of internal combustion engine is caused by the sharp rise of cylinder pressure in the combustion chamber. Due to high compression ratio and high pressure increase rate of internal combustion engine, the combustion noise generated by internal combustion engine at the same speed is much larger than the gasoline engine.

The generation mechanism of combustion noise can be described in the following two aspects [28]. On the one hand, when the combustible mixture is compressed and burned in the combustion chamber, the gas pressure will be intensely changed and will cause impact dynamic load to all the contacted components. These contacted components will produce complex structural coupling vibration under intense 
transient excitation. Then, the vibration can be transferred to the external surface structure of internal combustion engine through cylinder cover, cylinder liner, crank connecting rod mechanism, and so forth. Finally, the external surface structure vibration of internal combustion engine generates radiation noise to the surrounding environment. On the other hand, the fuel injection has a certain order, and the cylinder wall temperature is different, thus the combustion chamber is usually fired in multiple places. Then, the local pressure at several fire places will be increased sharply and spread to the surroundings. These generated pressure shock waves will be reflected in the combustion chamber wall, and the mediumhigh-frequency gas oscillation can be produced. Finally, it will further stimulate the internal combustion engine body vibration, and the medium-high-frequency noise can be radiated. The combustion noise generation and transfer path are shown in Figure 1.

Because the medium-high-frequency vibration attenuation is smaller than the low frequency part, the frequency of combustion noise is mainly concentrated at the mediumhigh-frequency range. The combustion process of internal combustion engine can be divided into four stages: fire delay period, rapid burning period, slow burning period, and after burning period. Only in the rapid burning period and slow burning period, the gas dynamic load will have enough energy to stimulate internal combustion engine body to vibrate and radiate the combustion noise. The gas dynamic load is closely related to the cylinder pressure rise rate.

\section{Internal Combustion Engine Test Platform}

3.1. Calculation Principle of Combustion Noise Based on Transfer Function Method. When the combustible mixture burns in the cylinder, the combustion pressure will act on the inner surface of internal combustion engine structure and incite the external surface of internal combustion engine to vibrate and radiate noise. This is defined as the combustion noise. Thus, the combustion noise can be considered as the response function based on the cylinder combustion pressure and internal combustion engine body structure. The combustion noise can be calculated by cylinder pressure and combustion noise transfer function. The specific calculation principle of combustion noise is shown in Figure 2.

From Figure 2, the calculation principle of combustion noise based on transfer function method can be divided into two steps:

(1) The first step is as follows. Firstly, the in-cylinder pulse pressure $F(f)$ and its radiation pulse sound pressure $Y(f)$ are measured by the independent combustion noise simulation test bench. Then, the internal combustion engine body structure combustion noise transfer function $H(f)$ can be calculated. It is defined as follows:

$$
H(f)=\frac{P_{Y F}(f)}{P_{F F}(f)} .
$$

Through the first step, the combustion noise transfer function $H(f)$ can be accurately obtained.
(2) The second step is as follows. When the internal combustion engine is operating in normal conditions, the cylinder pressure $P(f)$ is measured. Then, the measured cylinder pressure $P(f)$ and the combustion noise transfer function $H(f)$ are utilized to calculate the combustion noise $C(f)$. The calculation formula of combustion noise is defined as follows:

$$
C(f)=H(f) \times P(f) .
$$

Through the second step, the independent pure combustion noise $C(f)$ can be calculated.

3.2. Test Bench. The test bench is mainly included the 4120SG diesel engine, ignition system, accelerometer, microphone, cylinder pressure sensor, computer, and so forth. The main technical parameters of 4120SG diesel engine are shown in Table 1.

In the test, the ignition system is a key part. The traditional battery ignition system contains power supply, ignition switch, ignition coil, distributor, and spark plug. In this test, because the internal combustion engine is in a shutdown state, the ignition system does not need to achieve the automatic ignition and continuous ignition. It is mainly requires the power supply, ignition coil, and injectorshaped spark plug. The self-designed ignition system device is shown in Figure 3.

From Figure 3, the $12 \mathrm{~V}$ battery supplies power to the ignition system. When the manual switch is closed, the current is generated in the primary winding of ignition coil. As the current increases, the ignition coil will store the magnetic field energy. Then, when the manual switch is cut off, the stored magnetic field energy in the primary winding of ignition coil can quickly disappear, and the secondary winding will produce a high induced voltage. The produced high voltage is applied to the spark plug. It can strike the clearance between spark plug electrodes and generate spark. Finally, the combustible mixture in the cylinder can be ignited.

In the process of the test, considering that internal combustion engine is a compression ignition mode without ignition device and the ignition device needs to be installed in the position of the original fuel injector, the self-designed ignition system device is similar to the shape of the injector. The injector-shaped spark plug is mainly composed of central electrode, side electrode, sealed insulating layer, metal shell, and copper washer. The injector-shaped spark plug can bring the high voltage in the secondary winding of ignition coil into the cylinder. Then, the spark can be created between the central electrode and side electrode to ignite the combustible mixture. The injector-shaped spark plug is shown in Figure 4.

The test equipment mainly contains $7013 \mathrm{C} / \mathrm{CA}$ piezoelectric pressure sensor, 5018A1000 charge amplifier, B\&K 4189 capacitive microphone, PXIE-1078 chassis, PXIe-4492 ultra-wideband data acquisition card, Labview integrated data acquisition system, and computer. The range of $7013 \mathrm{C} / \mathrm{CA}$ piezoelectric pressure sensor is $25 \mathrm{MPa}$. Due to the high resistance of $7013 \mathrm{C} / \mathrm{CA}$ piezoelectric pressure 


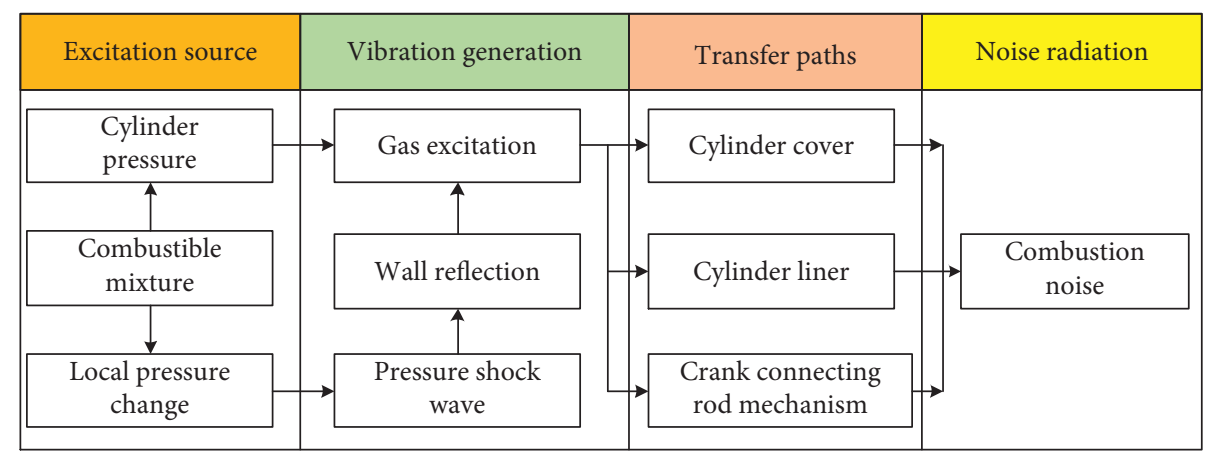

Figure 1: Combustion noise generation and transfer path in an internal combustion engine.

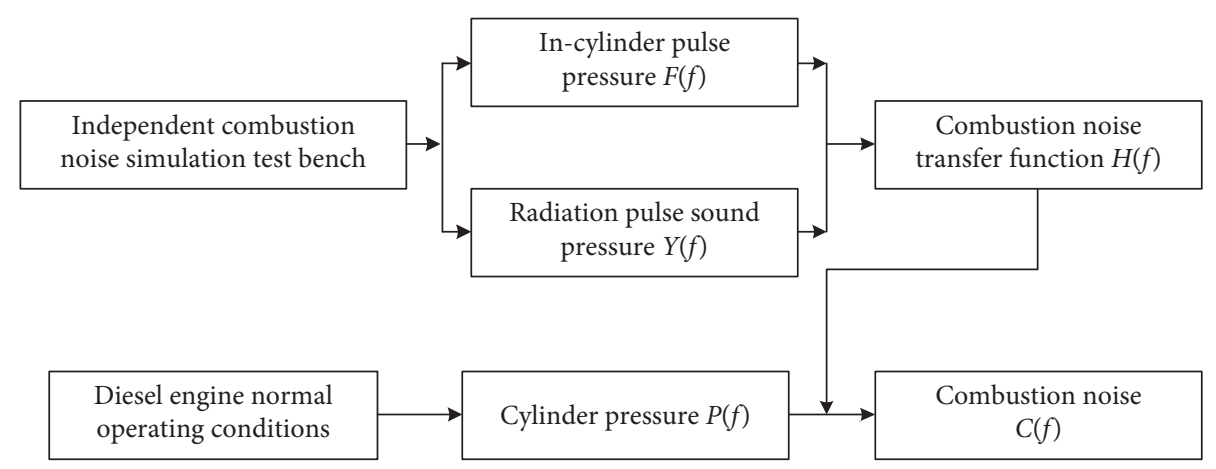

FIGURE 2: Calculation principle of combustion noise.

TABLE 1: Main technical parameters of 4120SG diesel engine.

\begin{tabular}{lc}
\hline Characteristics & Parameters \\
\hline Number of cylinders & 4 \\
Ignition sequence & $1-3-4-2$ \\
Rated power & $48.5 \mathrm{~kW}$ \\
Rated speed & $1500 \mathrm{rpm}$ \\
Stroke number & 4 \\
Cylinder diameter & $120 \mathrm{~mm}$ \\
Piston stroke & $140 \mathrm{~mm}$ \\
Compression ratio & $17: 1$ \\
Single cylinder displacement & $1.58 \mathrm{~L}$ \\
Cylinder burst pressure & $75 \mathrm{bar}$ \\
Minimum distance between piston top and cylinder & $1.0 \sim 1.3 \mathrm{~mm}$ \\
head bottom &
\end{tabular}

sensor, the output signal is very weak. Therefore, the 5018A1000 charge amplifier is added at the end of the $7013 \mathrm{C} / \mathrm{CA}$ piezoelectric pressure sensor. The sensitivity of 5018A1000 charge amplifier is $50 \mathrm{mV} /$ bar. The B\&K 4189 capacitive microphone diameter is $1 / 2$ inch, the frequency response range is $6.3 \mathrm{~Hz}-20 \mathrm{kHz}$, and the sensitivity is $50 \mathrm{mV} / \mathrm{Pa}$. The PXIe-1078 chassis has five hybrid slots and three PXI Express slots. The PXIe-4492 ultra-wideband data acquisition card has 24-bit analog-to-digital converter resolution, and the maximum voltage range is $\pm 10 \mathrm{~V}$. In the test, the sampling frequency of the signal is $204800 \mathrm{~Hz}$. The PXIe-1078 chassis has a built-in fan to enhance heat dissipation effect. The sound pressure level (SPL) of the fan is up to $49.96 \mathrm{~dB}(\mathrm{~A})$. In order to reduce the influence of fan noise on the test results, the data acquisition system is arranged in the internal combustion engine control room. The internal combustion engine control room and the internal combustion engine test bench laboratory are isolated through the soundproof door. The test equipment is shown in Figure 5.

According to the national standard GB/T1859-2000 "Reciprocating internal combustion engine-Measurement of emitted airborne noise-Engineering method and survey method," the three B\&K 4189 capacitive microphones are arranged 1 meter distance away from internal combustion engine. They are located on the longitudinal side of the no. 4 cylinder. It can be seen in Figure 6 .

From the free end to the flywheel end of internal combustion engine, the left microphone corresponds to the main slap side of the internal combustion engine, named as the main slap microphone, and the measured radiation pulse noise is named as the main slap side sound pressure. The upper microphone corresponds to the cylinder head top, named as the cylinder head top microphone, and the measured radiation pulse noise is named as the cylinder head top sound pressure. The right microphone corresponds to the internal combustion engine vice slap side, named as the vice slap side microphone, and the measured radiation pulse noise is named as the vice slap side sound pressure.

3.3. Combustible Mixture. Combustible, oxidizing agent, and ignition source are the three essential elements of combustion. In the test, the evaporated no. 97 gasoline is utilized as the combustible. The high concentration oxygen is employed as the oxidizing agent. The ignition system is used to ignite the combustible mixture. 


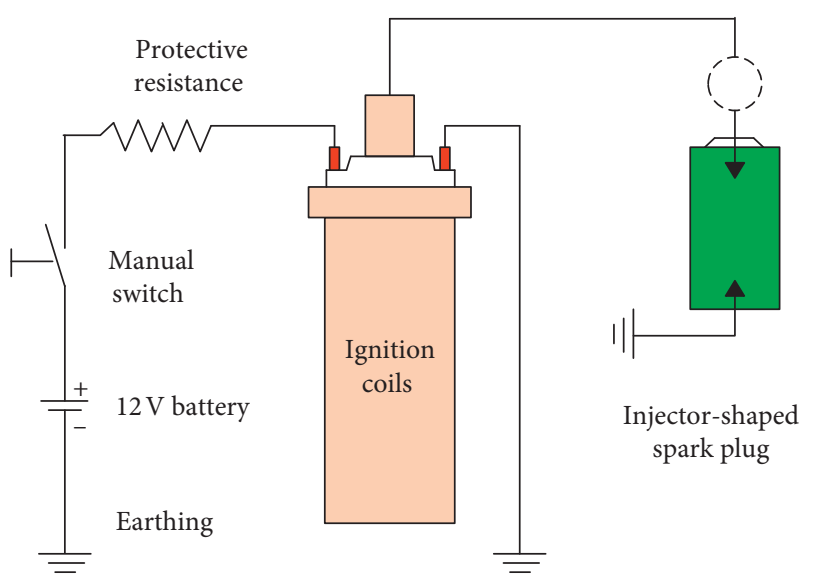

(a)

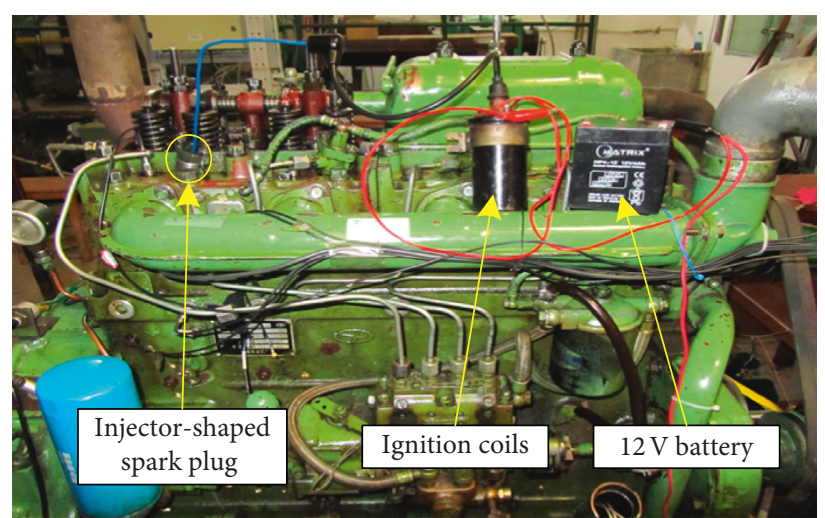

(b)

FIGURE 3: Self-designed ignition system device. (a) Ignition system structure diagram and (b) ignition system physical diagram.

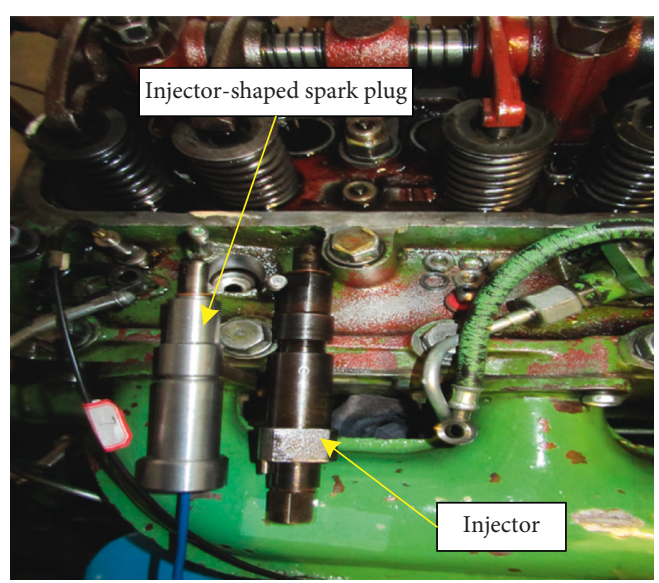

(a)

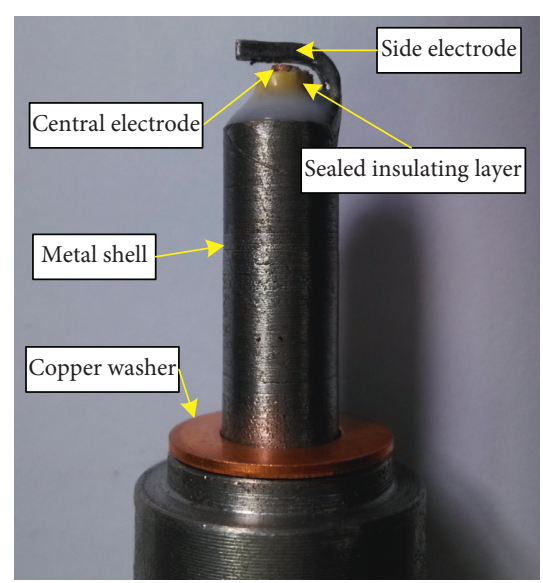

(b)

Figure 4: The injector-shaped spark plug. (a) Physical diagram. (b) Spark plug head.

It is required to determine the amount of oxygen and gasoline in the combustible mixture. According to the parameters of $4120 \mathrm{SG}$ diesel engine, the single cylinder displacement is $1.58 \mathrm{~L}$. Thus, assuming that the oxygen volume in the cylinder is $1.58 \mathrm{~L}$, the temperature is $100^{\circ} \mathrm{C}$, and the initial pressure is a standard atmospheric pressure. According to the ideal gas state equation, the amount of oxygen can be calculated. The ideal gas state equation is shown in the following equation:

$$
P V=n R T,
$$

where $P$ is gas pressure and the unit is $\mathrm{Pa} . V$ is gas volume, and the unit is $\mathrm{m}^{3} . n$ is the amount of substance of ideal gas, and the unit is mol. $R$ is gas constant, and in general, $R=$ $8.31441 \pm 0.00026 \mathrm{~J} /(\mathrm{mol} \cdot \mathrm{K}) . T$ is the system temperature, and the unit is $\mathrm{K}$.

Through calculation, the amount of oxygen in the cylinder is $0.052 \mathrm{~mol}$.

The main components of gasoline are $\mathrm{C}_{4}-\mathrm{C}_{12}$ aliphatic hydrocarbons and cyclic hydrocarbons. In this test, $\mathrm{C}_{8} \mathrm{H}_{18}$ is selected as the molecular formula of gasoline. In the ideal state, the evaporated gasoline is fully burned, and the chemical equation is as follows:

$$
2 \mathrm{C}_{8} \mathrm{H}_{18}+25 \mathrm{O}_{2}=16 \mathrm{CO}_{2}+18 \mathrm{H}_{2} \mathrm{O}
$$

Through calculation, the required quantity of gasoline is $640 \mu \mathrm{L}$.

3.4. Test Preparation. In the test, the internal combustion engine is in a static state. In order to obtain accurate combustion noise transfer function, the internal combustion engine system parameters in a static state should be close to normal working conditions as far as possible. In this test, the cooling water system, lubricating oil lubrication system, and fuel system should be worked normally to reduce the effect of structural elasticity and damping changes on the internal combustion engine test results. Therefore, before test, the internal combustion engine should work enough time to ensure that the cooling water temperature, oil temperature, and other parts' temperature are in balance. Then, stop the running internal combustion engine. 


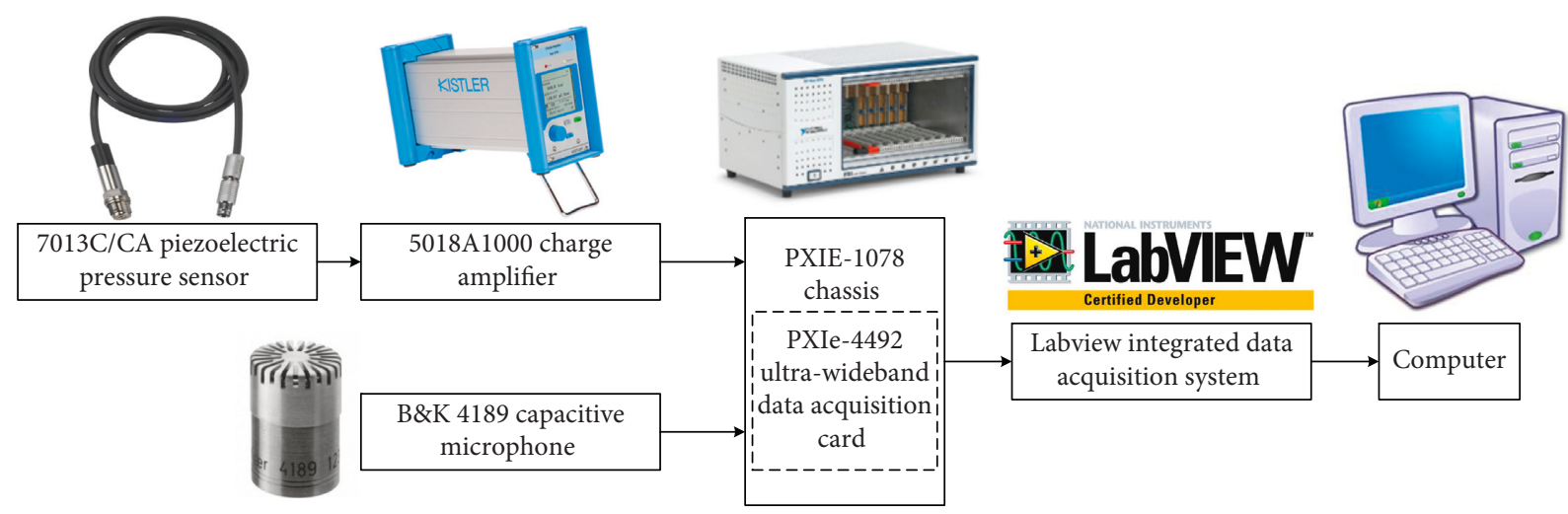

(a)

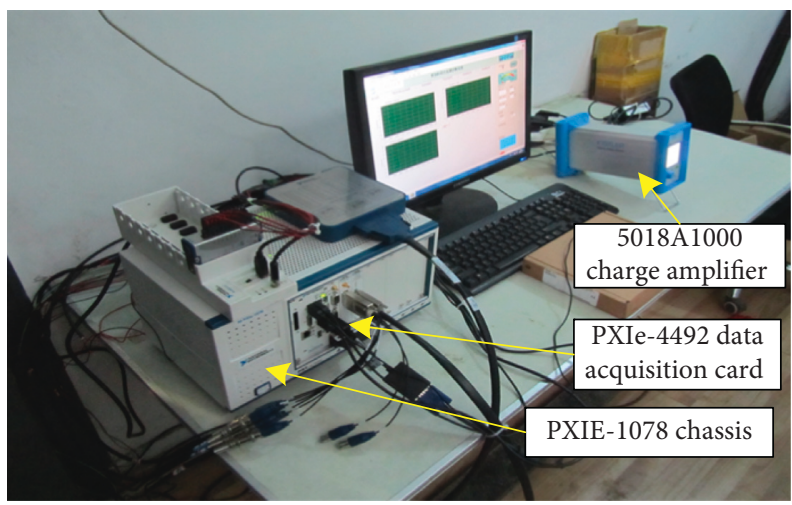

(b)

FIgURE 5: Test equipment. (a) Test system and (b) test site.

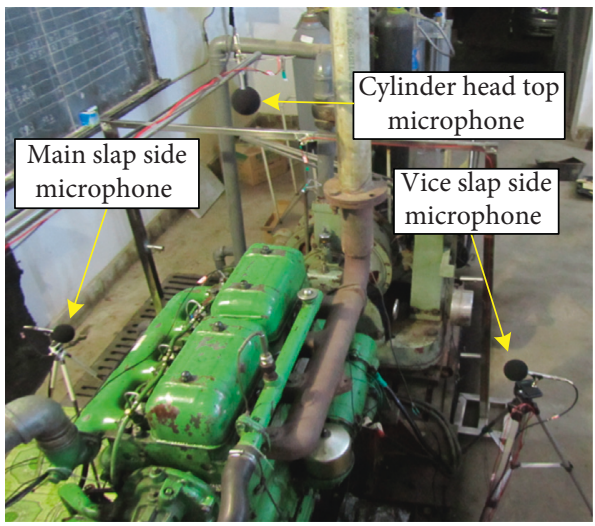

(a)

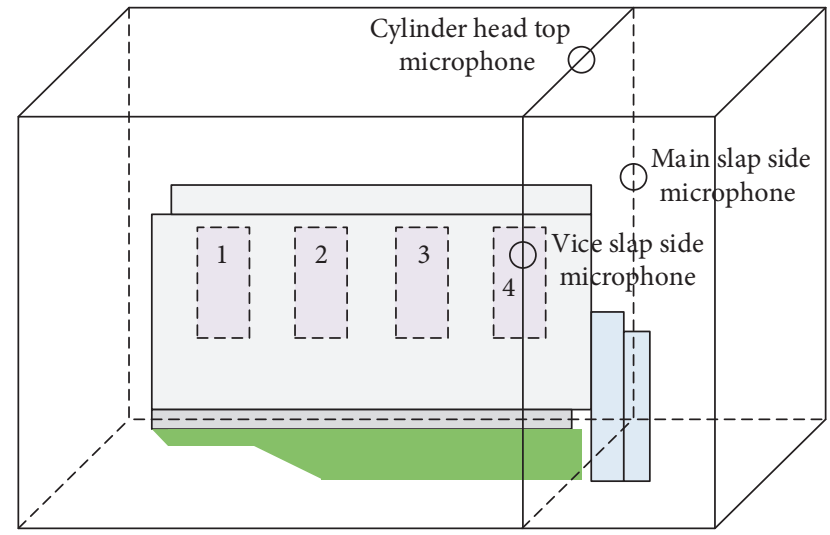

(b)

Figure 6: Microphone layout. (a) Test site diagram and (b) schematic diagram.

In addition, the charge amplifier should be preheated for 2 hours before the test. The measuring equipment needs to be calibrated. After the internal combustion engine is shut down, the injector of no. 4 cylinder needs to be removed. At this time, the total volume of no. 4 cylinder is directly connected to the external atmosphere. According to the rocker movement state and the gas distribution phase diagram (Figure 7), the position of the piston can be judged. Moreover, in order to avoid the influence of multiple reflections of sound waves in the cylinder head cover, the cylinder head cover of no. 4 cylinder needs to be removed.

First, the internal combustion engine needs to be turned a cycle to remove the exhaust gas in the combustion chamber. Then, the no. 4 cylinder piston is moved to the bottom dead center (TDC) position. The valve clearance is adjusted to make the inlet and exhaust valves closed. At this time, the total volume of the cylinder is $1.58 \mathrm{~L}$.

Through the fuel injector hole, the pure oxygen can be injected into the cylinder. At this moment, it can be 


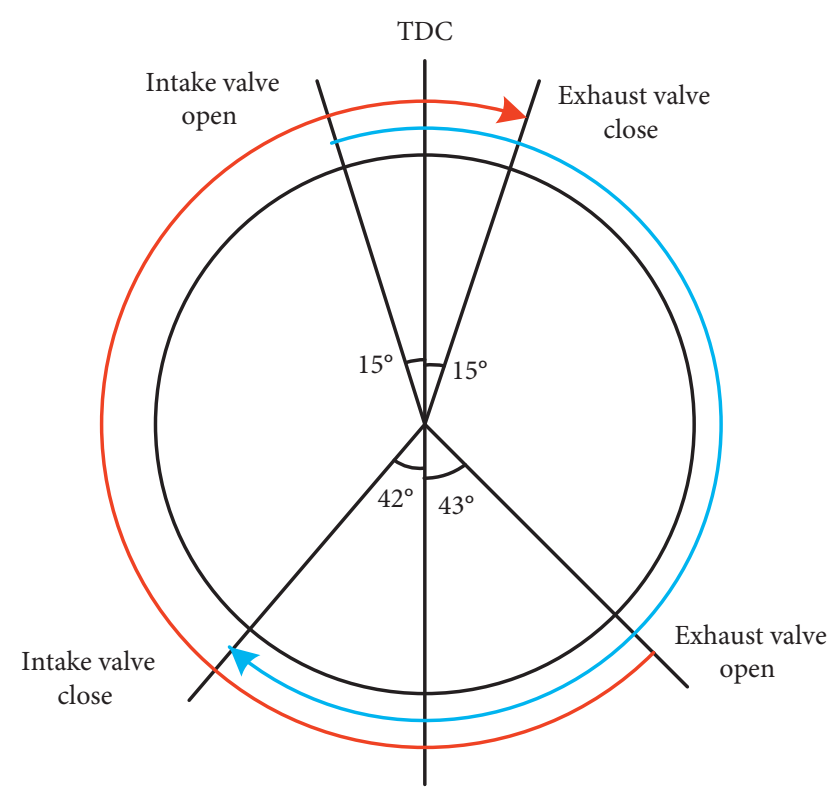

FIgURE 7: Gas distribution phase diagram.

considered that inside the cylinder is a standard atmospheric pressure of pure oxygen. The $640 \mu \mathrm{L}$ no. 97 gasoline is injected into the combustion chamber through an injector hole with a microinjector. Then, install the injector-shaped spark plug. After the liquid gasoline is completely evaporated in the sealed cylinder, the ignition system is utilized to ignite the combustible mixture in the cylinder. Through the data acquisition system, the cylinder pulse pressure signal $F(f)$ and its radiation pulse sound pressure signal $Y(f)$ are measured at the same time.

When the internal combustion engine is running under normal working conditions, the cylinder pressure $P(f)$ of no. 4 cylinder can be measured.

\section{Results and Discussion}

4.1. Combustion Noise Transfer Function. Through the internal combustion engine test, the measured cylinder pulse pressure signal $F(f)$ and each side radiation pulse sound pressure signal $Y(f)$ are shown in Figures 8 and 9 .

From Figure $8(\mathrm{a})$, in the time domain signal, the pulse pressure rise rate is up to $d p / d t=5 \mathrm{MPa} / \mathrm{s}$. It is caused by the rapid combustion of combustible mixture. From Figure 8(b), the low frequency band (below $600 \mathrm{~Hz}$ ) is corresponded to the high sound pressure level (SPL), and this segment is relatively flat that is associated with the highest pulse pressure. The medium frequency band $(600-2000 \mathrm{~Hz})$ sound pressure level is decreased faster than low frequency band. This segment is closely related to the maximum pulse pressure rise rate. The high frequency band (above $2000 \mathrm{~Hz}$ ) sound pressure level is declined rapidly. This segment is closely related to the high frequency pulse pressure oscillation.

From Figure 9(a), the power spectrum density (PSD) of main slap side sound pressure is mainly concentrated at $3238 \mathrm{~Hz}, 4513 \mathrm{~Hz}, 5150 \mathrm{~Hz}$, and $6519 \mathrm{~Hz}$. From Figure 9(b), the power spectrum density of cylinder head top sound pressure is mainly concentrated at $1538 \mathrm{~Hz}, 2463 \mathrm{~Hz}$,
$3306 \mathrm{~Hz}, 4144 \mathrm{~Hz}$, and $5969 \mathrm{~Hz}$. From Figure 9(c), the power spectrum density of vice slap side sound pressure is mainly concentrated at $1519 \mathrm{~Hz}, 3000 \mathrm{~Hz}$, and $4163 \mathrm{~Hz}$. From Figure 9, the power spectrum density of cylinder head top sound pressure is both rich and complex. This is because the cylinder head top microphone does not only receives the pulse pressure from the cylinder head top but also receives a portion of radiation pulse pressure from the main slap side and the vice slap side.

In order to evaluate the degree of reliability between the pulse pressure and each side radiation pulse sound pressure, the correlation coefficient is calculated. The higher the correlation coefficient is, the more reliable the measured signal is. The higher correlation coefficient means that the calculation result of combustion noise transfer function is more accurate.

Assuming that the input function is $x(t)$ and the response function is $y(t)$, the correlation coefficient is defined as follows:

$$
\gamma_{x y}^{2}(\omega)=\frac{\left|p_{x y}(\omega)\right|^{2}}{p_{x}(\omega) p_{y}(\omega)}
$$

where $p_{x}(\omega)$ and $p_{y}(\omega)$ are the self-power spectral density of input function $x(t)$ and output function $y(t)$, respectively, and $p_{x y}(\omega)$ is the cross power spectral density of the input and output functions.

The correlation coefficient between the pulse pressure and each side radiation pulse sound pressure is calculated. It is shown in Figure 10.

From Figure 10, it can be clearly seen that the correlation coefficient of vice slap side is greater than 0.5 , and it is obviously larger than the other two sides. As for the main slap side, it is close to the wall, and there is a certain degree of reflection and reverberation. Thus, there are many interference noises when the main slap side microphone is used to measure the radiation pulse sound pressure, resulting in low correlation coefficient. As for the cylinder head top, because the cylinder head top microphone can receive the noise from main slap side and vice slap side, the correlation coefficient is low. Therefore, the vice slap side sound pressure $Y(f)$ and the pulse pressure $F(f)$ are employed to calculate the combustion noise transfer function $H(f)$. The calculated results are shown in Figure 11.

From Figure 11, the calculated combustion noise transfer function reflects the combustion noise transfer characteristics from cylinder pressure signal to the combustion noise signal through the internal combustion engine body structure. The response value of the combustion noise transfer function is relatively high in the frequency range of $2000 \mathrm{~Hz}-5000 \mathrm{~Hz}$ and $7000 \mathrm{~Hz}-10000 \mathrm{~Hz}$. Below $2000 \mathrm{~Hz}$ and $5000 \mathrm{~Hz}-7000 \mathrm{~Hz}$, the response value of the combustion noise transfer function is relatively low.

4.2. $1500 \mathrm{rpm}$ and No-Load Condition (Normal Case). When the internal combustion engine is at $1500 \mathrm{rpm}$ and no-load condition, the measured cylinder pressure is shown in Figure 12. 


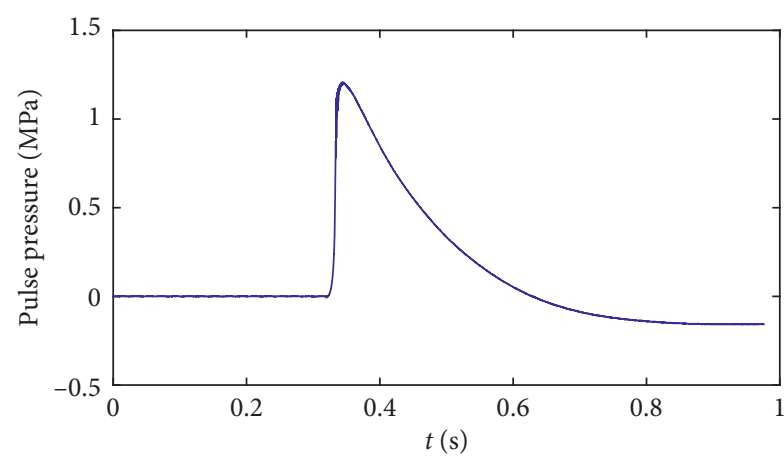

(a)

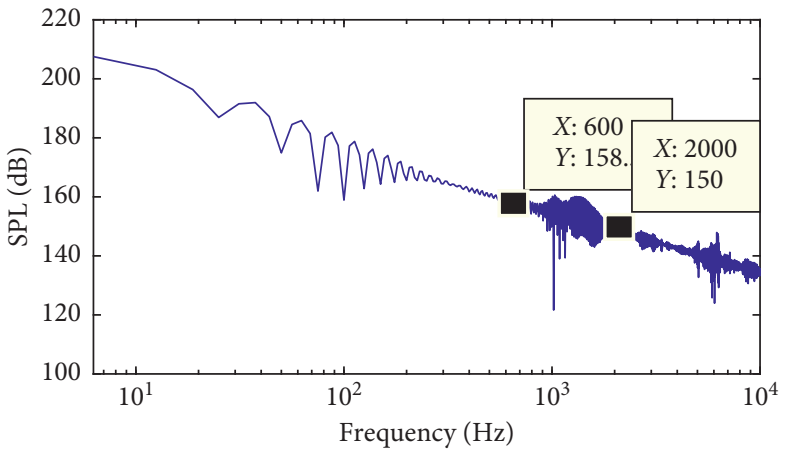

(b)

Figure 8: Cylinder pulse pressure. (a) Time domain signal and (b) amplitude-frequency curve.

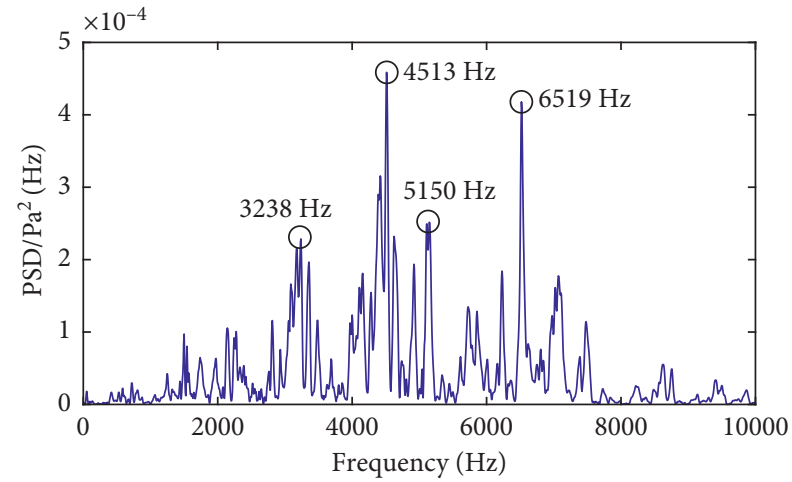

(a)

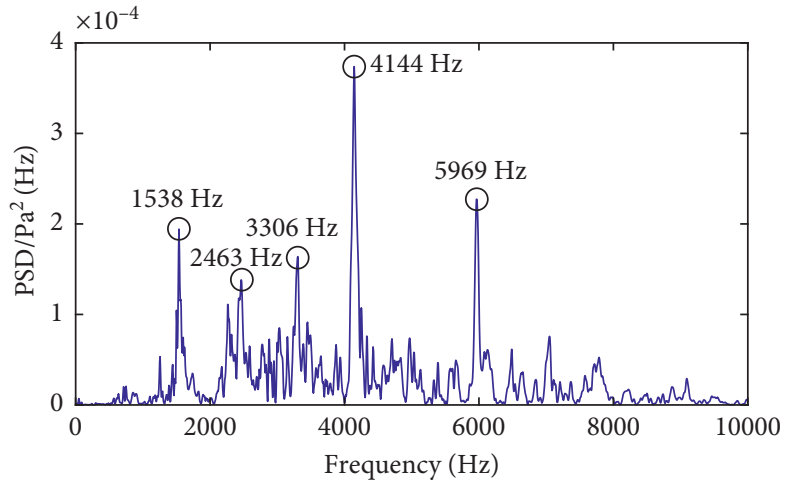

(b)

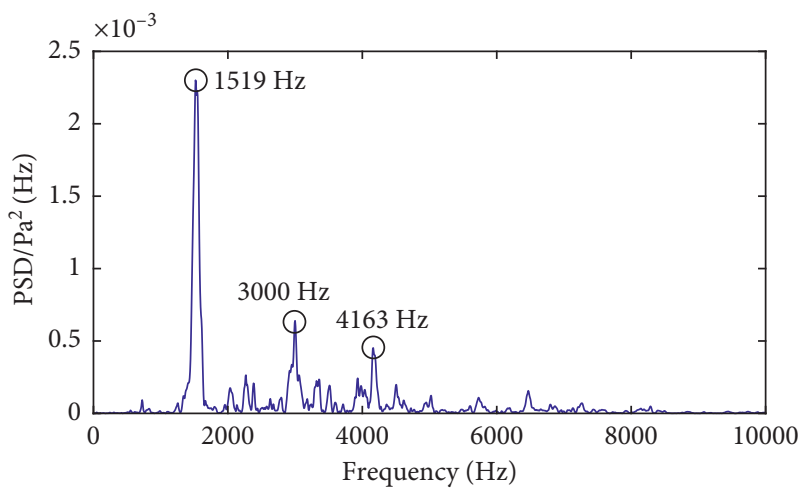

(c)

FIGURE 9: The PSD of each side pulse sound pressure. (a) Main slap side sound pressure PSD, (b) cylinder head top sound pressure PSD, and (c) vice slap side sound pressure PSD.

From Figure 12, the low frequency band (below $600 \mathrm{~Hz}$ ) corresponds to the high sound pressure level (SPL). The SPL of $600 \mathrm{~Hz}$ reaches to $186.5 \mathrm{~dB}$. The change in low frequency band is relatively flat. The low frequency band occupies most of the total cylinder pressure energy, but the attenuation of the low frequency through the internal combustion engine body structure is large, thus the radiation noise is small. The SPL of medium frequency band $(600-2000 \mathrm{~Hz})$ is relatively low. The high frequency band (above $2000 \mathrm{~Hz}$ ) is fluctuated obviously compared to low frequency band and medium frequency band.

Through the measured cylinder pressure signal and the calculated combustion noise transfer function, the independent pure combustion noise is calculated. It is shown in Figure 13.

From Figure 13, the frequency components of independent pure combustion noise are mainly concentrated in the vicinity of $1100 \mathrm{~Hz}$ and $1400 \mathrm{~Hz}$ (medium frequency 


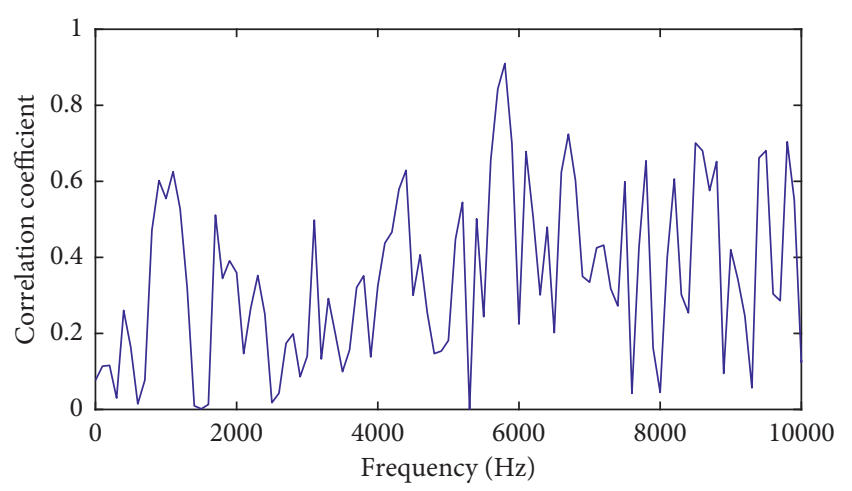

(a)

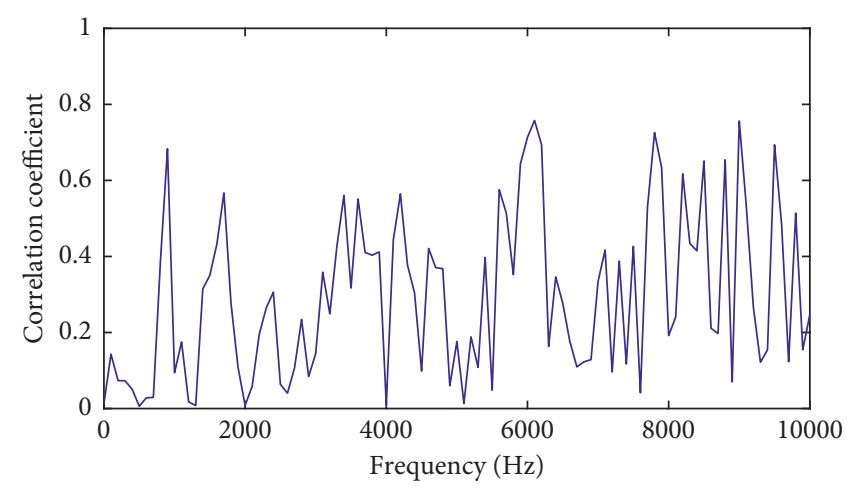

(b)

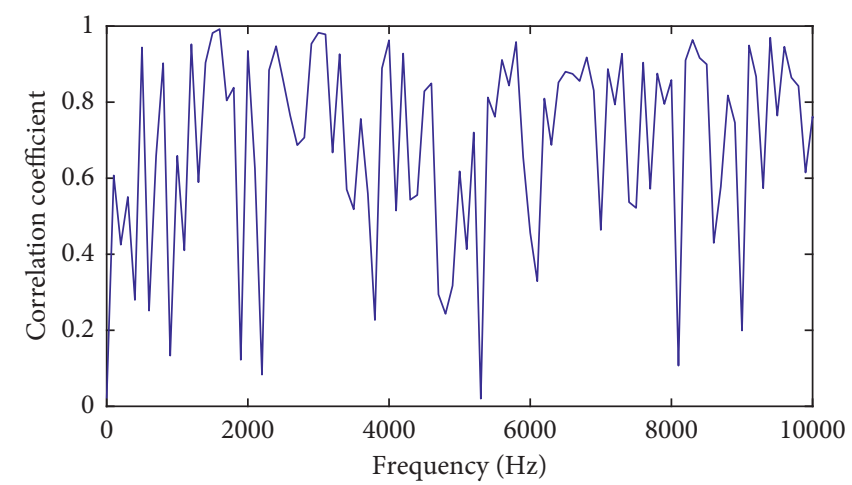

(c)

Figure 10: Correlation coefficient calculation results. (a) Main slap side correlation coefficient, (b) cylinder head top correlation coefficient, and (c) vice slap side correlation coefficient.

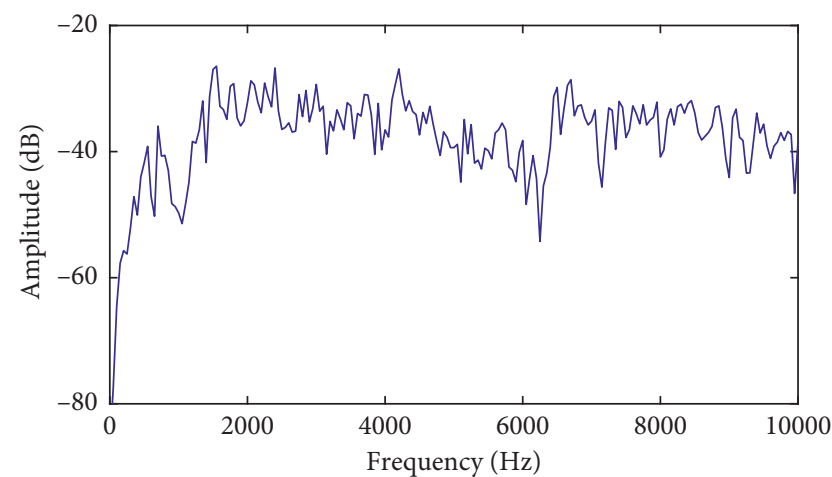

FIGURE 11: Calculated combustion noise transfer function by test.

band) and $3000 \mathrm{~Hz}$ (high frequency band). The amplitude of $1400 \mathrm{~Hz}$ is approximately four times the amplitude of $1100 \mathrm{~Hz}$ and $3000 \mathrm{~Hz}$. In addition, the independent pure combustion noise has almost no other frequency components.

4.3. $800 \mathrm{rpm}$ and No-Load Condition. When the internal combustion engine is running at $800 \mathrm{rpm}$ and no-load condition, the cylinder pressure can be measured. Combining the calculated combustion noise transfer function, the independent pure combustion noise is calculated. It is shown in Figure 14.

From Figure 14, the frequency components of independent pure combustion noise are still mainly concentrated in the vicinity of $1100 \mathrm{~Hz}$ and $1400 \mathrm{~Hz}$ (medium frequency band) and $3000 \mathrm{~Hz}$ (high frequency band). The amplitude at $1400 \mathrm{~Hz}$ is the largest. Compared with Figure 13, on the whole, the amplitude of the frequency in Figure 14 is smaller than that in Figure 13. It is shown that the independent pure combustion noise of internal combustion engine at low speed is lower than that of high speed.

4.4. Mechanical Noise. The main noise sources of internal combustion engine include combustion noise, mechanical noise, and aerodynamic noise. Combustion noise and mechanical noise account for a large proportion of the total noise of internal combustion engine. Aerodynamic noise is relatively small. When the combustion noise is calculated, the mechanical noise can be obtained by subtracting combustion noise from the total noise of the internal combustion engine. When the internal combustion engine is at $1500 \mathrm{rpm}$ and no-load condition and $800 \mathrm{rpm}$ and no-load condition, the calculated mechanical noise is shown in Figure 15.

From Figure 15, it can be seen the mechanical noise has many frequency components. When the diesel engine is at $1500 \mathrm{rpm}$ and no-load condition, the frequency components of mechanical noise are mainly focused on $711 \mathrm{~Hz}, 1244 \mathrm{~Hz}$, $1600 \mathrm{~Hz}, 2222 \mathrm{~Hz}$, and $2933 \mathrm{~Hz}$. When the diesel engine is at $800 \mathrm{rpm}$ and no-load condition, the frequency components of mechanical noise are mainly focused on $355 \mathrm{~Hz}$, $1156 \mathrm{~Hz}, 1956 \mathrm{~Hz}, 3022 \mathrm{~Hz}$, and $3644 \mathrm{~Hz}$. The mechanical 


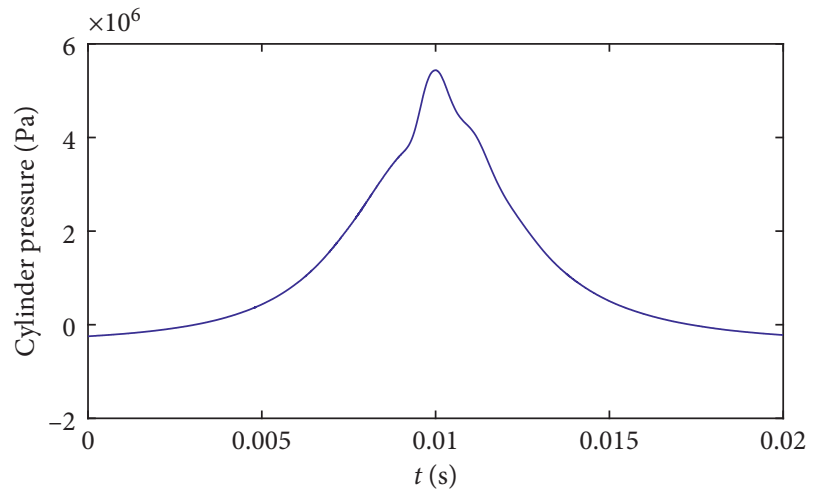

(a)

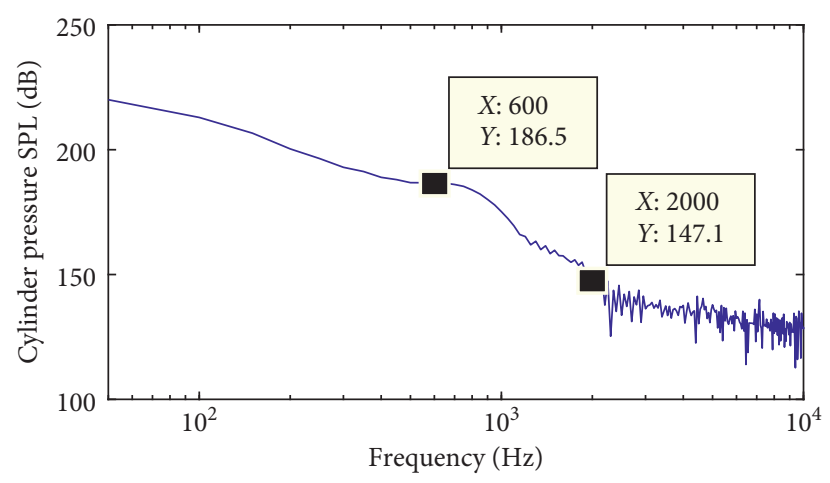

(b)

Figure 12: Cylinder pressure. (a) Time domain signal and (b) amplitude-frequency curve.

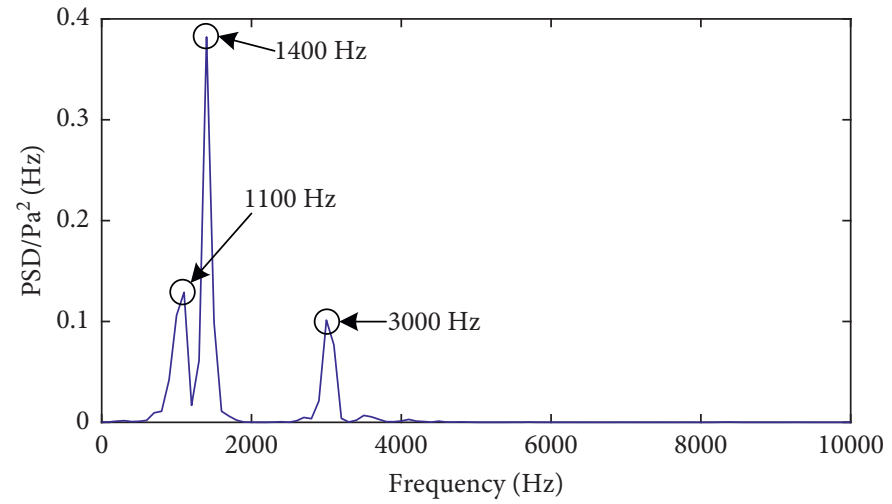

(a)

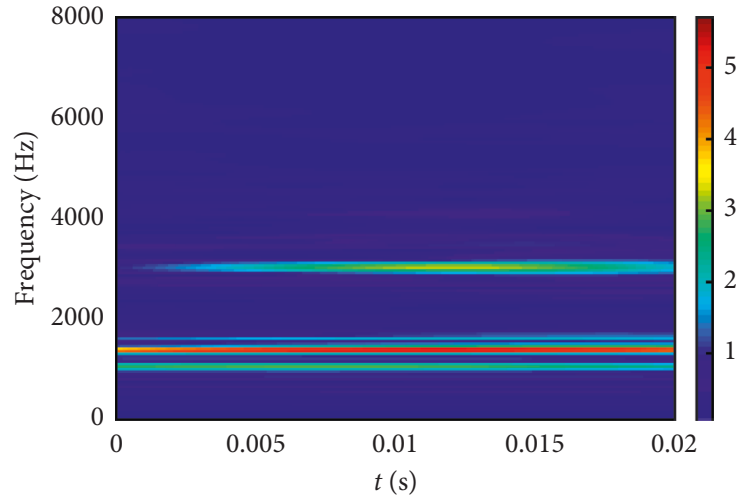

(b)

Figure 13: Calculated combustion noise of internal combustion engine at $1500 \mathrm{rpm}$ and no-load condition. (a) Spectrum and (b) timefrequency diagram.

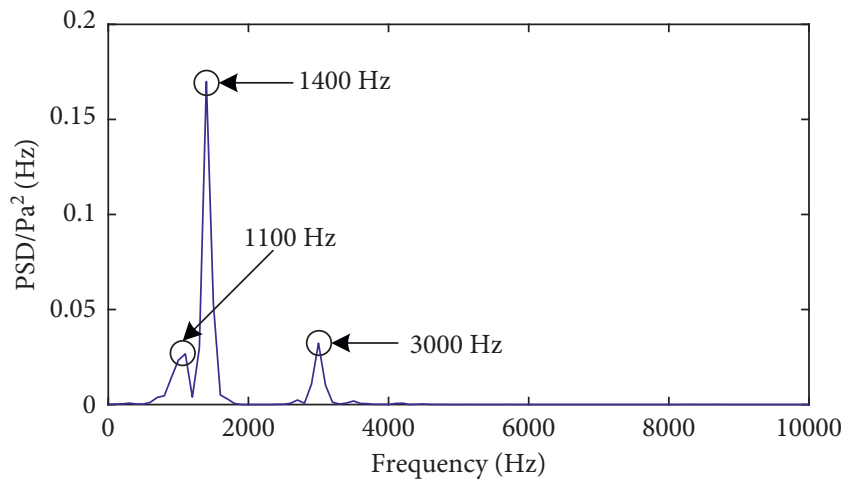

(a)

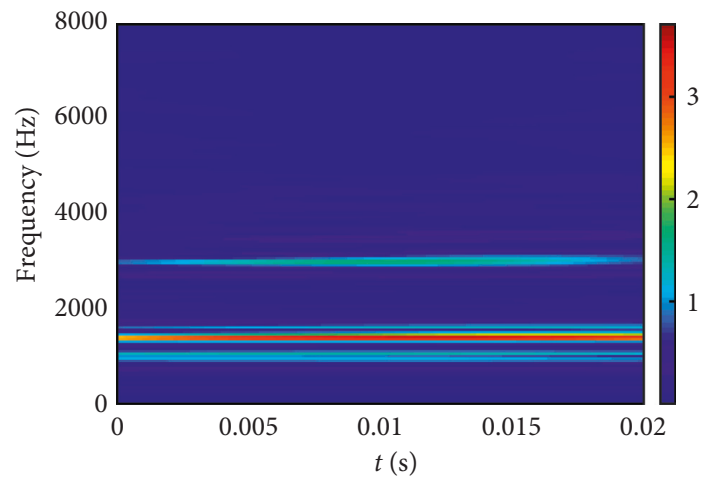

(b)

FIGURE 14: Calculated combustion noise of internal combustion engine at $800 \mathrm{rpm}$ and no-load condition. (a) Spectrum and (b) timefrequency diagram.

noise includes piston slap noise, air valve knock noise, gear meshing noise, fuel injection pump noise, etc. The piston slap noise is mainly caused by the impact between the piston and the cylinder liner. The air valve knock noise is mainly caused by the impact of valve opening and closing. The gear meshing noise is generated by the collision and friction between teeth and teeth during the gear meshing process. The fuel injection pump noise is related to the oil injection pressure and burning time of internal combustion engine. When the diesel engine is in different conditions, the frequency component of mechanical noise will have a certain difference. It needs to be further researched. 


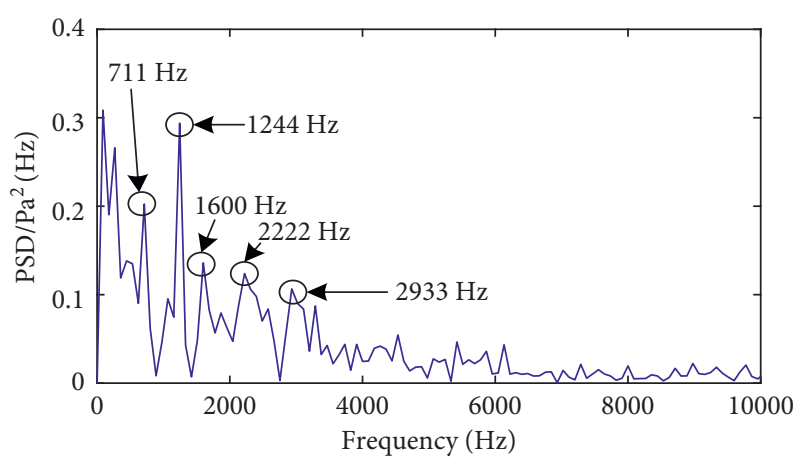

(a)

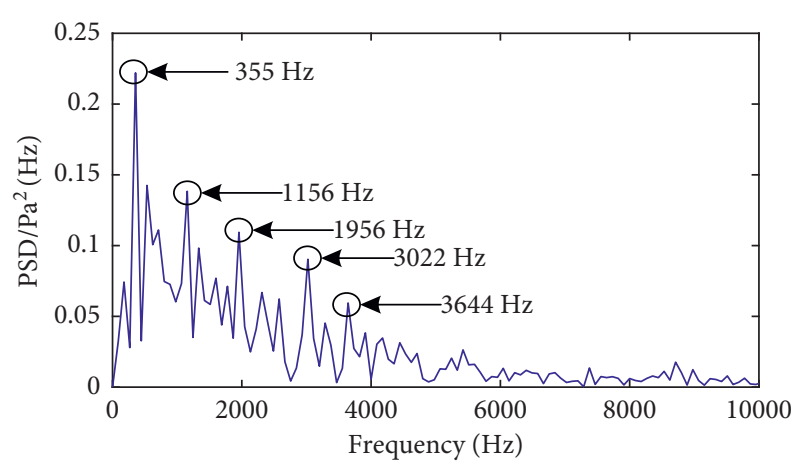

(b)

FIGURE 15: Mechanical noise. (a) $1500 \mathrm{rpm}$ and no-load condition and (b) $800 \mathrm{rpm}$ and no-load condition.

4.5. Verification Analysis. The internal combustion engine vibration test method and the combustion noise empirical formula calculation method are further carried out to verify the calculation results of independent pure combustion noise.

\subsubsection{Internal Combustion Engine Vibration Test Method.} In the combustion process, the cylinder pressure stimulates the cylinder liner to vibrate, and the vibration is transmitted to internal combustion engine body vice slap side. Then the vice slap side outer surface vibration can produce the vice slap side combustion noise to the surrounding environment. Therefore, the vice slap side vibration is related to the vice slap side combustion noise. The power spectral density of vice slap side vibration can be utilized to evaluate the accuracy of the calculated independent pure combustion noise.

The lance acceleration sensor LC0158T is utilized to measure the vice slap side vibration signal. The sensitivity of lance acceleration sensor LC0158T is $30 \mathrm{mV} / \mathrm{g}$, the maximum range is $166 \mathrm{~g}$, the resolution is $0.0007 \mathrm{~g}$, and the frequency response range is $0-10000 \mathrm{~Hz}$. The vice slap side vibration test point is shown in Figure 16.

In the test, in order to retain the useful components and eliminate the high frequency components, the low-pass filter is used to remove high-frequency components above $10 \mathrm{kHz}$ in the vibration signals.

The vice slap side vibration signals are respectively measured at $1500 \mathrm{rpm}$ and no-load condition and $800 \mathrm{rpm}$ and no-load condition, respectively. Because the unit of vibration signal is $\mathrm{g}$ and the unit of combustion noise is $\mathrm{Pa}$, the normalization needs to be carried out. Through calculation, the spectrum of measured vibration signal and independent pure combustion noise is shown in Figure 17.

From Figure 17, when the internal combustion engine is, respectively, at $1500 \mathrm{rpm}$ and no-load condition and $800 \mathrm{rpm}$ and no-load condition, the frequency of independent pure combustion noise is basically consistent with the frequency of the measured vibration signal. Especially near $1400 \mathrm{~Hz}$ and $3000 \mathrm{~Hz}$, the frequency amplitude of independent pure combustion noise and the measured vibration signal are both prominent. However, in Figure 17(a), the vibration signal in the vicinity of $2000-2600 \mathrm{~Hz}, 6000 \mathrm{~Hz}, 7000 \mathrm{~Hz}$, and $9000 \mathrm{~Hz}$

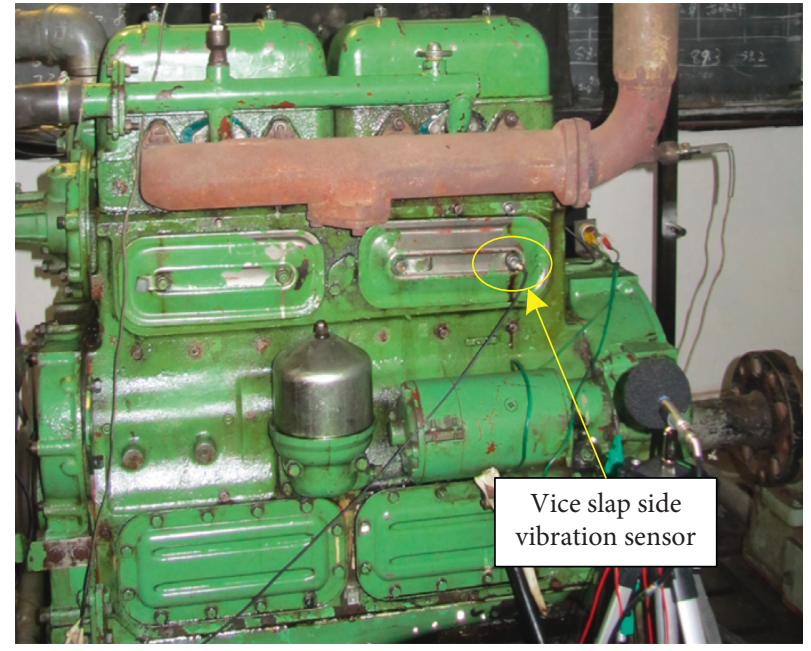

FIGURE 16: Vice slap side vibration test point.

has frequency components. In Figure 17(b), the vibration signal in the vicinity of $2000-2600 \mathrm{~Hz}, 4000 \mathrm{~Hz}$, and $8500-$ $9500 \mathrm{~Hz}$ has frequency components. These frequency components are mainly caused by the mechanical excitation from other parts. Independent pure combustion noise does not have these frequency components. Thus, through the internal combustion engine vibration test method, the measured vice slap side vibration signal showed accuracy and effectiveness of the calculated independent pure combustion noise.

\subsubsection{Combustion Noise Empirical Formula Calculation} Method. The combustion noise empirical formula calculation method is mainly refers to combustion noise measurement principle of combustion noise meter. The calculation formula is as follows:

$$
C=201 g \frac{\operatorname{RMS}(P(t))}{P_{\text {ref }}}+A+\mathrm{CAV},
$$

where $C$ represents combustion noise signal, and the unit is $\mathrm{dB}$. $\mathrm{RMS}(P(t))$ represents the root mean square value of the filtered cylinder pressure, and the unit is bar. $P_{\text {ref }}$ represents reference sound pressure, the unit is bar, and $P_{\text {ref }}=2 \times 10^{-10}$ bar. $A$ represents the frequency 


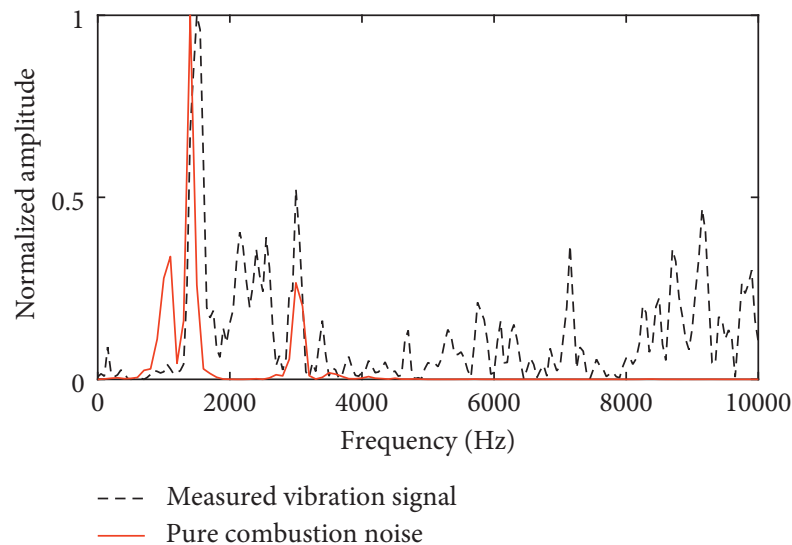

(a)

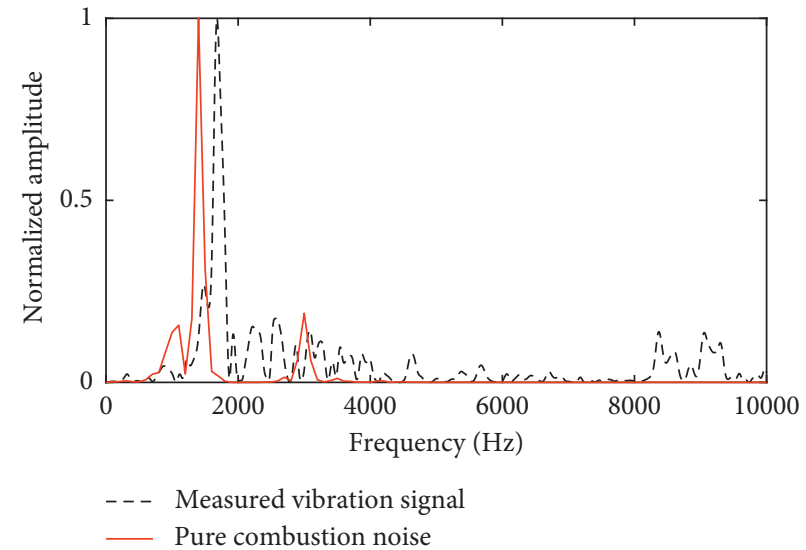

(b)

FIGURE 17: Spectrum of measured vibration signal and independent pure combustion noise. (a) $1500 \mathrm{rpm}$ and no-load condition and (b) $800 \mathrm{rpm}$ and no-load condition.

TABLE 2: Frequency characteristic parameter of $A$ weighted network.

\begin{tabular}{lccc}
\hline Center frequency $(\mathrm{Hz})$ & A weighted value $(\mathrm{dB})$ & Center frequency $(\mathrm{Hz})$ & $A$ weighted value $(\mathrm{dB})$ \\
\hline 100 & -19.1 & 1000 & 0 \\
125 & -16.1 & 1250 & 0.6 \\
160 & -13.4 & 1600 & 1.0 \\
200 & -10.9 & 2000 & 1.2 \\
250 & -8.6 & 2500 & 1.3 \\
315 & -6.6 & 3150 & 1.2 \\
400 & -4.8 & 4000 & 1.0 \\
500 & -3.2 & 5000 & 0.5 \\
630 & -1.9 & 6300 & -0.1 \\
800 & -0.8 & 8000 & -1.1 \\
\hline
\end{tabular}

TABLE 3: Empirical parameters of engine body structure attenuation.

\begin{tabular}{lccc}
\hline Center frequency $(\mathrm{Hz})$ & Transfer function value $(\mathrm{dB})$ & Center frequency $(\mathrm{Hz})$ & Transfer function value $(\mathrm{dB})$ \\
\hline 100 & -143.0 & 1000 & -96.5 \\
125 & -137.5 & 1250 & -93.3 \\
160 & -132.4 & 1600 & -90.8 \\
200 & -127.8 & 2000 & -89.7 \\
250 & -122.3 & 2500 & -89.5 \\
315 & -117.2 & 3150 & -90.6 \\
400 & -112.3 & 4000 & -94.2 \\
500 & -108.2 & 5000 & -99.2 \\
630 & -103.8 & 6300 & -105.6 \\
800 & -100.0 & 8000 & -116.0 \\
\hline
\end{tabular}

characteristic parameters of $A$ weighted network. CAV represents the empirical parameters of engine body structure attenuation.

The frequency characteristic parameters of $A$ weighted network are shown in Table 2.

The empirical parameters of engine body structure attenuation are shown in Table 3.

The cylinder pressure signal is measured by test. Then, the combustion noise empirical formula calculation method is utilized to calculate the experience value of combustion noise. The calculation results are shown in Figure 18.
From Figure 18, it can be seen that the combustion noise calculation results of empirical formula calculation method and simulation test bench method are in good agreement below $2000 \mathrm{~Hz}$. Combined with Figures 13 and 14, the frequency of calculated combustion noise by simulation test bench is mainly concentrated at $1100 \mathrm{~Hz}, 1400 \mathrm{~Hz}$, and $3000 \mathrm{~Hz}$. The $1100 \mathrm{~Hz}$ and $1400 \mathrm{~Hz}$ are below $2000 \mathrm{~Hz}$. Therefore, the combustion noise calculation results at $1100 \mathrm{~Hz}$ and $1400 \mathrm{~Hz}$ are very good. However, from Figure 18, it can be seen that there are some differences in the combustion noise calculation results above $2000 \mathrm{~Hz}$. 


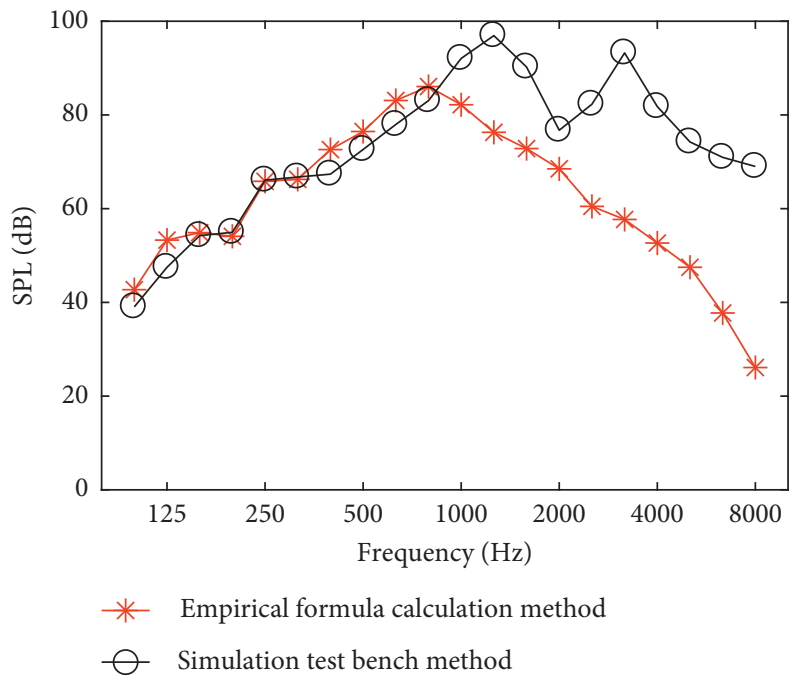

(a)

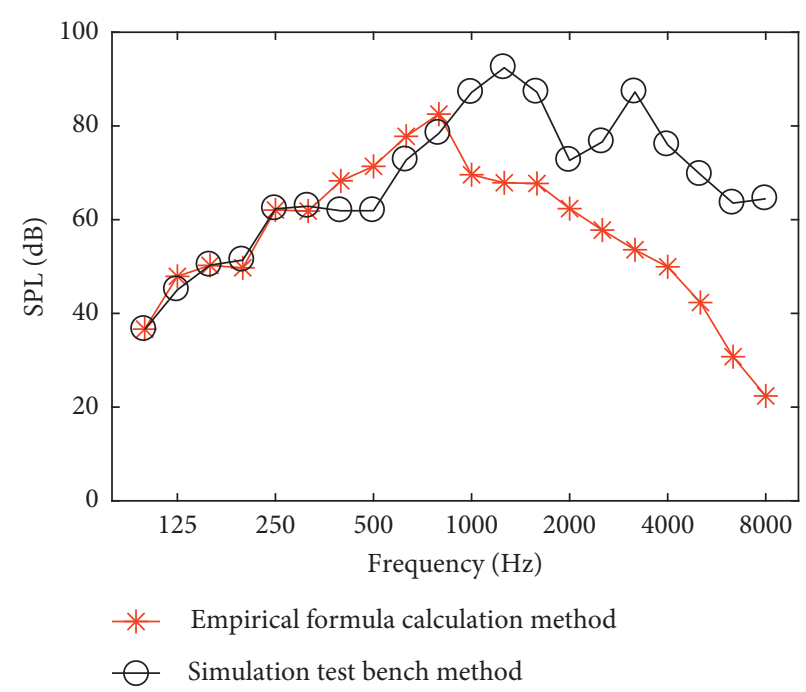

(b)

FIGURE 18: Comparison of combustion noise calculation results. (a) $1500 \mathrm{rpm}$ and no-load condition and (b) $800 \mathrm{rpm}$ and no-load condition.

The combustion noise at $3000 \mathrm{~Hz}$ has a certain degree of error. The reason for the error is that the engine body structure attenuation parameters in the empirical formula calculation method have a certain degree of difference with the engine body structure attenuation parameters of the 4120SG diesel engine in the high frequency part (above $2000 \mathrm{~Hz}$ ). The engine body structure attenuation parameters in the empirical formula calculation method are empirical parameter values, and they have some difference with a specific type of $4120 \mathrm{SG}$ diesel engine. The combustion noise calculation results have a certain difference in $3000 \mathrm{~Hz}$ frequency component. But the overall trend of the calculation results is consistent. Therefore, the independent pure combustion noise obtained is accurate.

\section{Conclusions}

In order to ignite the combustible mixture (pure oxygen and no. 97 gasoline), considering that internal combustion engine is a compression ignition mode without ignition device and the ignition device needs to be installed in the position of the original fuel injector, the ignition device which is similar to the shape of the injector is self-designed and implemented in detail. It has simple and practical features, and it is very useful and reliable in the test.

Before test, the internal combustion engine needs to work enough time to ensure the internal combustion engine parameters in a static state are close to normal working conditions as far as possible. Then, in the test, the in-cylinder pulse pressure signal and its radiated pulse sound pressure signal are measured at the same time. They are used for calculating the combustion noise transfer function. Thus, the combustion noise transfer function can be calculated accurately.

When the internal combustion engine is at $1500 \mathrm{rpm}$ and no-load condition and $800 \mathrm{rpm}$ and no-load condition, the independent pure combustion noise is calculated by the measured cylinder pressure and the calculated transfer function. Experimental results show that the frequency components of independent pure combustion noise are both concentrated at $1100 \mathrm{~Hz}, 1400 \mathrm{~Hz}$, and $3000 \mathrm{~Hz}$. In addition, the two verification methods are further carried out to show accuracy and effectiveness of the obtained independent pure combustion noise.

Independent pure combustion noise acquisition experimental platform can provide reference for the acquisition of other independent noise sources. In addition, the obtained independent pure combustion noise can provide a theoretical reference for fault diagnosis and noise reduction plan of internal combustion engines.

\section{Data Availability}

The MAT-file data used to support the findings of this study are available from the corresponding author upon request.

\section{Conflicts of Interest}

The authors declare that they have no conflicts of interest.

\section{Acknowledgments}

This work was supported by the National Natural Science Foundation of China (Grant nos. 51079118 and 51279148) and the China Scholarship Fund (201806950033).

\section{References}

[1] E. G. Giakoumis, D. C. Rakopoulos, and C. D. Rakopoulos, "Combustion noise radiation during dynamic internal combustion engine operation including effects of various biofuel blends: a review," Renewable and Sustainable Energy Reviews, vol. 54, pp. 1099-1113, 2016. 
[2] A. Broatch, X. Margot, R. Novella et al., "Combustion noise analysis of partially premixed combustion concept using gasoline fuel in a 2-stroke engine," Energy, vol. 107, pp. 612-624, 2016.

[3] E. A. King and E. Murphy, "Environmental noise_'Forgotten' or 'Ignored' pollutant?," Applied Acoustics, vol. 112, pp. 211-215, 2016.

[4] N. Roswall, O. Raaschou-Nielsen, S. S. Jensen et al., "Longterm exposure to residential railway and road traffic noise and risk for diabetes in a Danish cohort," Environmental Research, vol. 160, pp. 292-297, 2018.

[5] G. A. Luz, "Noise management: international regulations," in Reference Module in Earth Systems and Environmental Sciences, Elsevier, Amsterdam, Netherlands, 2013.

[6] I. Papanicolopulu, "Warships and noise regulation: the international legal framework," Marine Pollution Bulletin, vol. 63, no. 1-4, pp. 35-39, 2011.

[7] D. Yang, Z. Wang, B. Li et al., "A hybrid acoustic holography technique for moving sound source identification based on wave superposition algorithm," Noise Control Engineering Journal, vol. 60, no. 1, pp. 113-120, 2012.

[8] X. Wang, F. Bi, C. Liu et al., "Blind source separation and identification of internal combustion engine noise based on independent component and wavelet analysis," in Proceedings of International Conference on Electrical and Control Engineering, pp. 113-116, IEEE, Wuhan, China, March 2011.

[9] W. Cheng, Z. Zhang, G. Zhu et al., "Noise source identification and localization of mechanical systems based on an enhanced independent component analysis," Journal of Vibration and Control, vol. 22, no. 4, pp. 1128-1142, 2014.

[10] M. E. Badaoui, J. Danière, F. Guillet et al., "Separation of combustion noise and piston-slap in internal combustion engine-part I: separation of combustion noise and pistonslap in internal combustion engine by cyclic Wiener filtering," Mechanical Systems and Signal Processing, vol. 19, no. 6, pp. 1209-1217, 2005.

[11] J. Drouet, Q. Leclère, and E. Parizet, "Experimental modeling of Wiener filters estimated on an operating internal combustion engine," Mechanical Systems and Signal Processing, vol. 50-51, pp. 646-658, 2015.

[12] H. B. Huang, X. R. Huang, M. L. Yang et al., "Identification of vehicle interior noise sources based on wavelet transform and partial coherence analysis," Mechanical Systems and Signal Processing, vol. 109, pp. 247-267, 2018.

[13] K. Torii, "Method using multiple regression analysis to separate engine radiation noise into the contributions of combustion noise and mechanical noise in the time domain," SAE International Journal of Engine, vol. 7, no. 3, pp. 1502$1513,2014$.

[14] I. Hirano, M. Kondo, Y. Uraki et al., "Using multiple regression analysis to estimate the contributions of engineradiated noise components," JSAE Review, vol. 20, no. 3, pp. 363-368, 1999.

[15] H. Q. Wei, G. Q. Shu, X. Y. Liang et al., "Multi-regression analysis of the first-level influence model of combustion noise," Chinese Internal Combustion Engine Engineering, vol. 27, no. 4, pp. 66-69, 2006.

[16] Z. Q. Wang, J. Wu, C. Wei et al., "Multiple regression analysis of gasoline engine combustion noise," Mechanical Science and Technology for Aerospace Engineering, vol. 36, no. 8, pp. 1265-1271, 2017.

[17] X. Y. Liang and G. Shu, "Identification of complex noise sources of diesel engine based on coherent power spectrum analysis," Transactions of CSICE, vol. 24, no. 4, pp. 344-350, 2006.
[18] D. Blacodon and S. Lewy, "Source localization of turboshaft engine broadband noise using a three-sensor coherence method," Journal of Sound and Vibration, vol. 338, pp. 250262, 2015.

[19] J. Yao, Y. Xiang, S. Qian et al., "Noise source separation of internal combustion engine by combining binaural sound localization method and blind source separation method," Mechanical Systems and Signal Processing, vol. 96, pp. 303320, 2017.

[20] F. Bi, L. Li, J. Zhang et al., "Source identification of gasoline engine noise based on continuous wavelet transform and EEMD-RobustICA," Applied Acoustics, vol. 100, pp. 34-42, 2015.

[21] J. Zhang, J. Wang, J. Lin et al., "Internal combustion engine noise source identification based on EEMD, coherent power spectrum analysis and improved AHP," Measurement Science and Technology, vol. 26, no. 9, article 095010, 2015.

[22] J. Yao, Y. Xiang, S. Qian et al., "Noise source identification of internal combustion engine based on variational mode decomposition and robust independent component analysis," Applied Acoustics, vol. 116, pp. 184-194, 2017.

[23] G. Q. Shu, H. Q. Wei, and R. Han, "The transfer function of combustion noise in DI-internal combustion engine," in Proceedings of SAE 2005 Noise and Vibration Conference and Exhibition, pp. 10088-10093, Long Beach, CA, USA, 2005.

[24] K. Jafarian, M. Mobin, R. Jafari-Marandi et al., "Misfire and valve clearance faults detection in the combustion engines based on a multi-sensor vibration signal monitoring," Measurement, vol. 128, pp. 527-536, 2018.

[25] N. Cavina, A. Businaro, N. Rojo et al., "Combustion and Intake/exhaust systems diagnosis based on acoustic emissions of a GDI TC engine," Energy Procedia, vol. 101, pp. 677-684, 2016.

[26] G. Chiatti, O. Chiavola, F. Palmieri et al., "Diagnostic methodology for internal combustion diesel engines via noise radiation," Energy Conversion and Management, vol. 89, pp. 34-42, 2015.

[27] D. Santos-Domínguez, S. Torres-Guijarro, A. Cardenal-López et al., "ShipsEar: an underwater vessel noise database," Applied Acoustics, vol. 113, pp. 64-69, 2016.

[28] E. G. Giakoumis, A. M. Dimaratos, and C. D. Rakopoulos, "Experimental study of combustion noise radiation during transient turbocharged internal combustion engine operation," Energy, vol. 36, no. 8, pp. 4983-4995, 2011. 


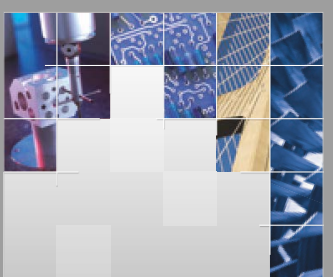

\section{Enfincering}
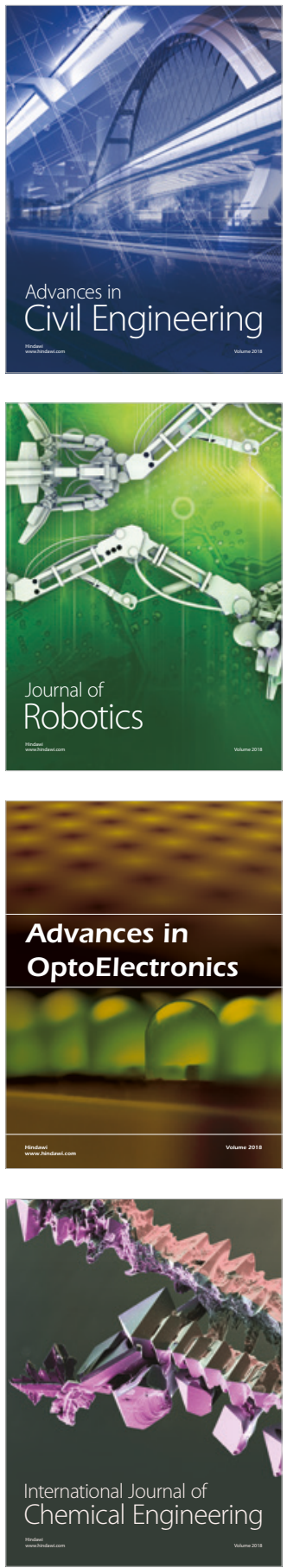

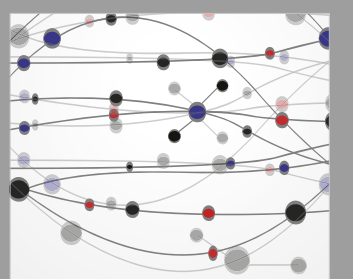

\section{Rotating \\ Machinery}

The Scientific World Journal

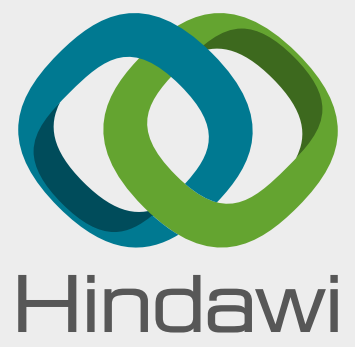

Submit your manuscripts at

www.hindawi.com
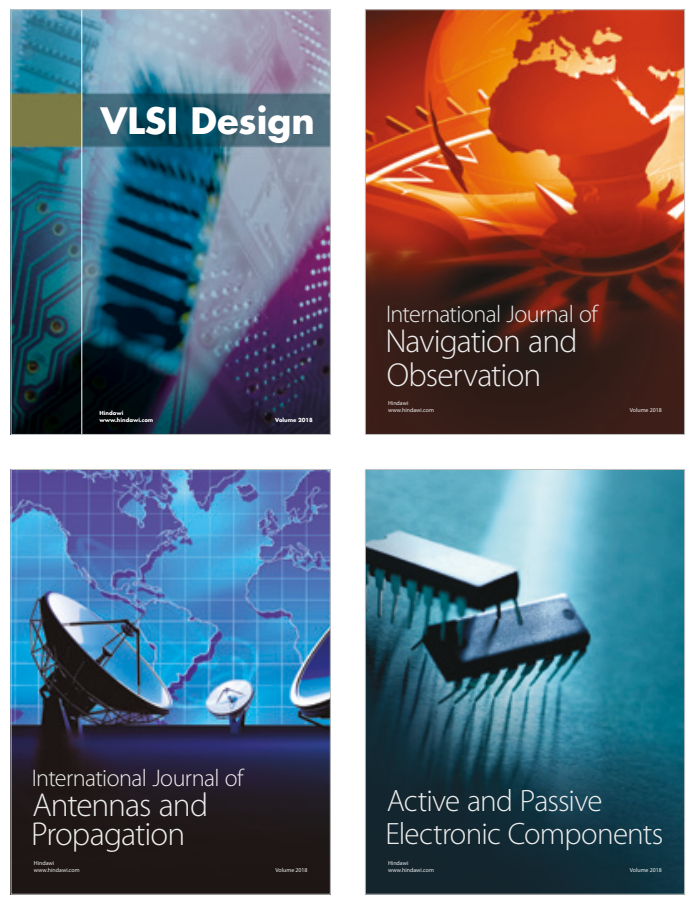
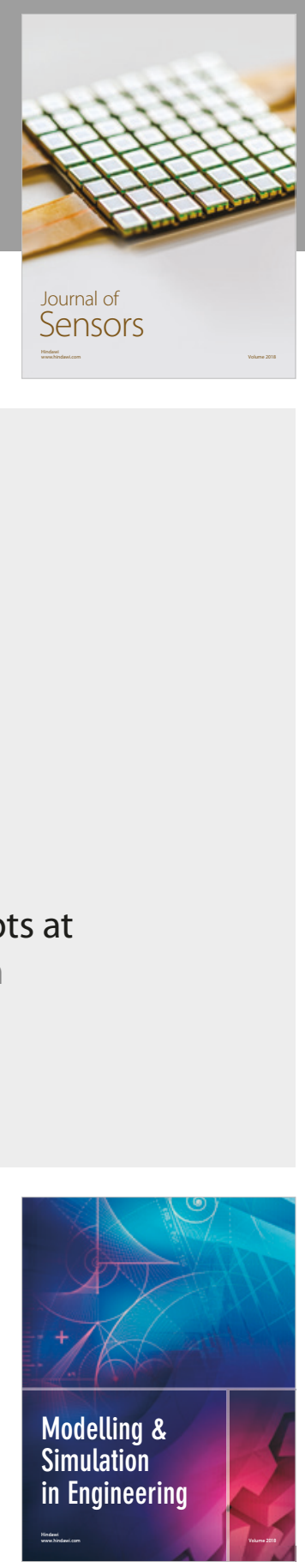

\section{Advances \\ Multimedia}
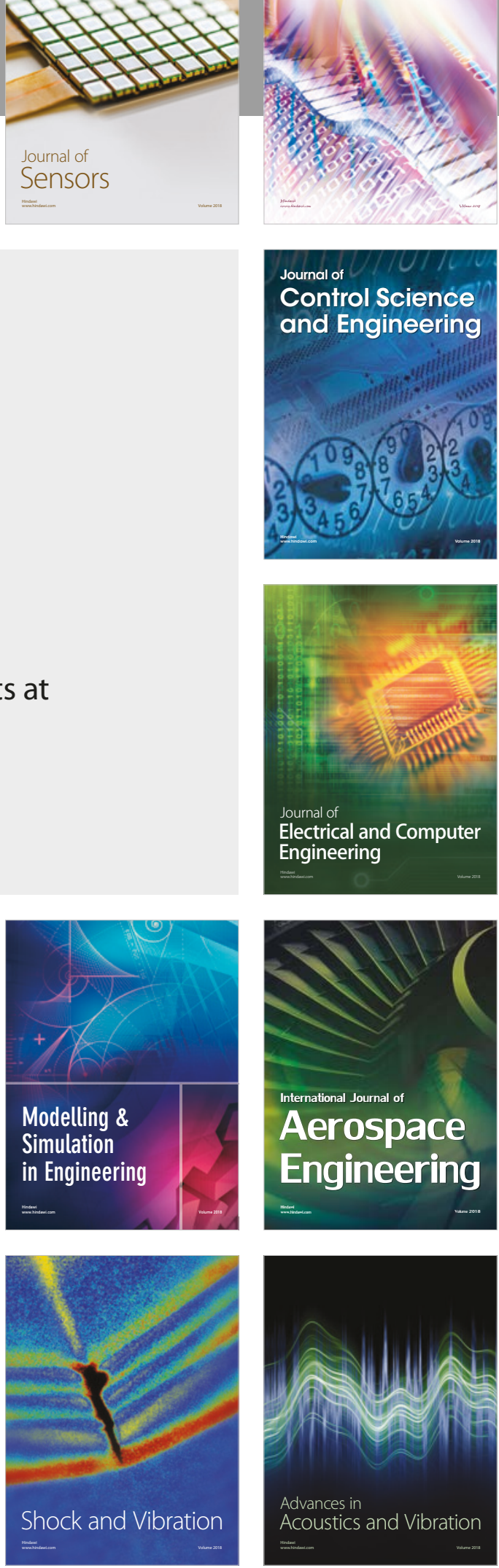